\title{
The Effect of Schema-vs-translation-based Teaching on Learning English in High Schools
}

\author{
Ebrahim Khodadady (Corresponding author) \\ Ferdowsi University of Mashhad, Iran \\ Reyhaneh Hesarzadeh \\ Ferdowsi University of Mashhad, Iran
}

\begin{abstract}
The present research project was conducted to explore the effect of schema-based teaching (SBT) and translation-based teaching (TBT) on vocabulary knowledge, structure and reading comprehension ability of forty-one female grade one high school (G1HS) students. They were assigned to SBT and TBT groups on the basis of their performance on a schema-based cloze multiple choice item test (S-Test) designed on the textbooks they had read in previous years. While the SBT views single words and phrases as the schemata constituting texts and provides appropriate contexts for the learners to learn them in English, the TBT adopts sentences as the basic units of language and encourages learners to translate their constituting words into their mother language. Upon offering the same textbook to the SBT and TBT groups an achievement S-Test, matching vocabulary test, multiple choice item grammar test designed on the textbook along with a reading comprehension test developed on unseen texts were administered to the groups to find out which approach was more effective. The results showed the superior performance of SBT group over the TBT group on the unseen reading comprehension test. The SBT group did not, however, perform significantly better than the TBT group on the achievement $S$-Test, grammar, and vocabulary tests. The findings are discussed and suggestions are made for future research.
\end{abstract}

Index Terms — schema theory, learning, teaching, testing

\section{INTRODUCTION}

Today learning foreign languages such as English has become an educationally indispensible necessity throughout the whole world. Many language teaching methods have, therefore, been developed and employed to meet the necessity. They range from grammar-translation method to communicative language teaching and task-based approach (LarsenFreeman, (2000; Richards \& Rodgers, 2001). Due to the diversity of teaching approaches and their difference in language and learning theories, selecting an appropriate method to achieve the intended educational objectives has, therefore, become a matter of great concern to language teachers.

Of all the methods and approaches, grammar-translation has had a worldwide application (Brown, 2000). This approach which dominated foreign language teaching from 1840s to 1940s (Richards \& Rodgers, 2001) focuses on direct translation from target language to the native one (Brown, 2000; Larsen-Freeman, 2000; Richards \& Rodgers, 2001). Recent decades have, however, witnessed an increasing interest toward the application of schema theory to language teaching. This theory highlights the role of background knowledge in language learning by adopting schema as a cognitive framework (Carrell, 1984). It is composed of ideas organized on the basis of its semantic, syntactic and discoursal relationships with other schemas or schemata (Khodaday \& Elahi, 2012). Indeed, schemata are abstract mental structures which help the acquired knowledge to be stored in memory in a systematic manner (Melendez \& Pritchard, 1985) helping learners organize and interpret large amount of information.

Schemata are acquired through experiences gained in life (Ajideh, 2003). When new information is encountered, it is understood by relating it to other schemata. The acquisition of the new information will thus depend on and be shaped by its being fitted to the previously stored schemata (Carrell, 1983, 1984; Khodadady \& Elahi, 2012). Imagine a child, as an example, whose schema of "cat" is a creature with four legs and a tail and two ears. Confronting a "dog" for the first time in life, s/he may call it a cat in order to interact with her environment. In this case the previously acquired knowledge makes the child call the dog, a cat. Thus, s/he has to adapt his or her schema to the new information. This process has largely been explained by two approaches followed in schema theory: macrostructural and microstructural (Khodadady \& Elahi, 2012; Khodadady, 1999).

\section{A. Macrostructural Approach}

Based on the macrostructural approach of schema theory, upon encountering the title of a text, readers invoke whatever background knowledge they have and then process and integrate the information presented in the entire text on the basis of their background knowledge. It defines schema as rhetorical knowledge, i.e. the knowledge to determine the text pattern, and tries to "explain the reading comprehension ability in terms of some broad terms such as scripts and 
genres" (Khodadady \& Elahi, 2012, p. 146). To the best knowledge of present researchers no scholar has been able to translate this approach into a coherent teaching approach so far due to its subjective nature.

\section{B. Microstructural Approach}

In contrast to macrostructural view, microstructural approach regards a text under comprehension as an entity comprised of specific schemata, i.e. single and phrasal words. The comprehension of a given schema within the text takes place not only by activating whatever background knowledge the reader has stored about it before but also by determining its contextual meaning by relating it to other schemata comprising the text. The depth of background knowledge and the ability to relate it to other schemata does in fact render the text partially or completely comprehensible to the reader. In order to study the functioning of schemata within texts, Khodadady (2008), Khodadady and Herriman (2000) and Khodadady, Pishghadam and Fakhar (2010) assigned them to three main domains: semantic, syntactic and parasyntactic,

Semantic schemata are the main concepts the authors have stored in their minds as their background knowledge. They are experienced in reality on a moment by moment basis and are represented by adjectives, adverbs, nouns and verbs in English. They are "open in nature" since new semantic schemata are met and learned during one's life. Syntactic schemata such as conjunctions, determiners, prepositions and pronouns depend, however, on semantic ones and are attached to them in order to confine their meanings within the variables of time and place. They are, therefore, few in type but many in number. Parasyntactic schemata are similar to syntactic ones in function but can be many in type as semantic schemata are. They comprise abbreviations, names, numerals and para-adverbs (Khodadady, 2008; Khodadady, 1999, Khodadady \& Javadi Mehr, 2012).

According to Khodadady and Elahi (2012), the identification and understanding of all semantic, syntactic and parasyntactic schemata in a text and establishing discoursal relationships among them results in the full comprehension of the text. Thus, the role of a language teacher is to help learners understand each and all the schemata comprising a text and then relate them to each other as intended by its author. They will learn a foreign language if they can activate their own schemata and put them side by side to produce their own version of text. The language proficiency of learners can thus be measured by their ability to understand and employ appropriate schemata to read and write texts of varying length.

\section{Microstructural Approach of Schema Theory and Foreign Language Teaching}

Shejbalova (2006) described Krashen's (1987) analysis of learners' linguistic outputs taught via TBT in a lucid manner. According to him, Krashen witnessed the students' errors even in applying simple rules. He, then, noticed the incomprehensibility of the students' sentences since they made hesitations while producing them. He came up with the idea that grammar-translation approach sacrifices comprehensibility and fluency for accuracy. In spite of having similar observations, many teachers in Iran still follow TBT in their classes.

Brown (2000) outlined some factors which make TBT popular; among them are few specialized skills on the part of teacher, easiness of constructing tests and the subjectivity of their being scored. Some scholars, however, tend to support some other methods which are more attentive to learners. Some, for example, suggest schema-based teaching (SBT) as Carrell and Floyd (cited in Ajideh, 2003) do. These scholars believe that language teachers' main responsibility is to help learners connect the new knowledge presented in texts to their previously acquired one in order to achieve educational objectives.

Similarly, Melendez and Pritchard (1985) believed that the application of background knowledge boosts one's comprehension and interpretation of new information. Thus, applying schema theory to foreign language reading comprehension promotes learning in language classes as confirmed by research findings. Pearson, Hansen and Gordon (1979), for example, showed that the students with well developed schemata did significantly better than those with less background knowledge. They concluded that developing schemata enhances the ability to do the task. (The conclusion is also supported in the literature on the macro structural view of schema theory as reviewed by Stott (2001).

Following the microstructural approach of schema theory, Khodadady and Elahi (2012) designed an experimental design to find out whether adopting the TBT and SBT as two distinct methods of teaching English for Special Purposes (ESP) brings about any significant difference in learners' achievement. Their result showed that the medical university students who learned the ESP via the SBT scored significantly higher on the achievement test than those sitting in the TBT classes. Similarly, Khodadady, Alavi, Pishghadam and Khaghaninezhad's (2012) study showed that the SBT applied to the teaching of ESP to undergraduate students majoring in theology results in significantly higher ESP achievement compared to TBT. The present study attempts to find out whether similar results will be obtained if grade 1 high school (G1HS) students are taught via SBT.

\section{Methodology}

\section{A. Participants}

Forty-one female G1HS students in Kuhsorkh region near Kashmar, Iran, were included in the study. Their age ranged from 14 to 16 . They all spoke Persian as their mother tongue. They had studied English only in grades 2 and 3 of guidance school. None was studying English anywhere other than the school while the experiment was conducted. 


\section{B. Instruments}

Five language tests were designed in the present study to fulfill various functions, i.e., pre S-Test, achievement STest, matching vocabulary, grammar, and reading comprehension tests.

\section{Pre S-Test}

In order to determine whether the SBT and TBT groups were homogeneous in terms of their English background, all the dialogues and passages comprising the English book 2 (Birjandi \& Soheili, 2009a) and English book 3 (Birjandi \& Soheili, 2009b) were parsed and categorised into domains and genera as shown in Table 1 . As can be seen, the 282 different types of semantic domain schemata (56.7\%) have been used in the two textbooks followed by $126(26.0 \%)$ parasyntactic and $86(17.3 \%)$ syntactic schemata, indicating that the majority of pre S-Test items must be semantic in nature. Based on the percetage of domain and genera types used in composing the textbooks, 83 schemata were chosen to develop the items on.

TABLE 1

FREQUENCY AND PERCENTAGE OF GENERA TOKENS AND TYPES COMPRISING GRADES 2 AND 3 OF GUIDANCE SCHOOL TEXTBOOKS

\begin{tabular}{|c|c|c|c|c|c|}
\hline \multirow{2}{*}{ Domain } & \multirow[t]{2}{*}{ Genus } & \multicolumn{2}{|l|}{ Tokens } & \multicolumn{2}{|l|}{ Types } \\
\hline & & Frequency & Percentage & Frequency & Percentage \\
\hline \multirow{4}{*}{ Semantic } & Adjectives & 54 & 2.7 & 33 & 6.6 \\
\hline & Nouns & 381 & 19.1 & 141 & 28.4 \\
\hline & Verbs & 215 & 10.8 & 97 & 19.5 \\
\hline & Total & 670 & 33.7 & 282 & 56.7 \\
\hline \multirow[t]{6}{*}{ Syntactic } & Conjunctions & 52 & 2.6 & 7 & 1.4 \\
\hline & Determiners & 254 & 12.8 & 30 & 6.0 \\
\hline & Prepositions & 140 & 7.0 & 12 & 2.4 \\
\hline & Pronouns & 253 & 12.7 & 21 & 4.2 \\
\hline & Syntactic verbs & 164 & 8.2 & 16 & 3.2 \\
\hline & Total & 863 & 43.4 & 86 & $\mathbf{1 7 . 3}$ \\
\hline \multirow[t]{7}{*}{ Para-syntactic } & Abbreviations & 66 & 3.3 & 23 & 4.6 \\
\hline & Interjections & 26 & 1.3 & 6 & 1.2 \\
\hline & Names & 178 & 8.9 & 44 & 8.9 \\
\hline & Numerals & 40 & 2.0 & 20 & 4.0 \\
\hline & Para-adverbs & 147 & 7.4 & 36 & 7.2 \\
\hline & Total & 457 & 23.0 & 129 & 26.0 \\
\hline & Total (All genera) & 1990 & 100.0 & 497 & 100.0 \\
\hline
\end{tabular}

As it can also be seen in Table 1 above, the parasyntactic domain contains genera such as names which play little role, if any, in learning English. For example, 44 transliterated Persian names such as Parvin and Reza have been used in the two textbooks whose inclusion in language tests would be questionable. For this reason more syntactic schemata were chosen to address the English structure. The pre S-Test thus consisted of $6(7.2 \%)$ adjectives, $2(2.4 \%)$ adverbs, 27 $(32.5 \%)$ nouns, $20(24.1 \%)$ verbs, $2(2.4 \%)$ conjunctions, $5(6.0 \%)$ determiners, $3(3.6 \%)$ prepositions, $7(8.4 \%)$ pronouns, $3(3.6 \%)$ syntactic verbs and $8(9.6 \%)$ para-adverbs (see Appendix).

A schema-based item (SBI) differs from traditional multiple choice items (MCIs) in being based on schema theory. When a given syntactic schema such as "my" is, for example, read, it activates the concept of possessing the person (or object) represented by the semantic schema that follows it, i.e., "father", in its readers' mind. They need to relate the pronoun "he" to "their father" and assign him the position of an agent who usually does many things such as "speaking", "listening", "saying" and "looking". However, they need to specify his intended action by focusing on the nouns "book", "friends" and "things" as its discoursally related schemata. Thus choosing the verbs "speaking", "listening", and "looking" as alternatives showing the nature of action is a distinctive feature of SBIs. By choosing verbs rather than adjectives, adverbs and nouns as the alternatives of SBI 10 and confining the selected verbs to those of "action" rather than "state", e.g., being and feeling, or "possession", e.g., have, establishes the common semantic feature shared between the keyed response and its alternatives and thus differentiates them from the "distracters" of traditional MCIs. Khodadady $(1997,1999)$ highlighted the distinction by referring to the alternatives of SBIs as "competitives".

EXAMPLE SBI

MY FATHER HAS A LOT OF BOOKS. ... HE ....10 ... BOOKS ARE OUR GOOD FRIENDS. THEY TEACH US A LOT OF THINGS.

\begin{tabular}{|l|l|l|l|l|l|l|l|l|}
\hline 10 & A & speaks & B & listens & C & says & looks & loks \\
\hline
\end{tabular}

\section{Achievement S-Test}

The first four lessons of English Book 3 (Birjandi, et al., 2012) taught to the SBT and TBT groups were parsed and categorized into their constituting semantic, syntactice and parasyntactic domains and genera to develop the contentbased achievement S-Test. As can be seen in Table 2, 726 schema tokens comprise the lessons of which 312 (43.0\%), $335(46.1 \%)$ and $79(10.9)$, are semantic, syntactic and parasyntactic, respectively. The type-based analysis of schemata, 
however, shows that $175(62.3 \%)$ are semantic followed by $75(26.7 \%)$ syntactic and $31(11.0 \%)$ of parasyntacic schemata.

TABLE 2

FREQUENCY AND PERCENTAGE OF GENERA TOKENS AND TYPES USED IN THE FIRST FOUR LESSONS OF ENGLISH BOOK 3

\begin{tabular}{|c|c|c|c|c|c|}
\hline \multirow{2}{*}{ Domain } & \multirow{2}{*}{ Genus } & \multicolumn{2}{|l|}{ Tokens } & \multicolumn{2}{|l|}{ Types } \\
\hline & & Frequency & Percentage & Frequency & Percentage \\
\hline \multirow{5}{*}{ Semantic } & Adjectives & 33 & 4.5 & 25 & 8.9 \\
\hline & Adverbs & 8 & 1.1 & 7 & 2.5 \\
\hline & Nouns & 160 & 22 & 66 & 23.5 \\
\hline & Verbs & 111 & 15.3 & 77 & 27.4 \\
\hline & Total & 312 & 43 & 175 & 62.3 \\
\hline \multirow{6}{*}{ Syntactic } & Conjunctions & 29 & 4 & 8 & 2.8 \\
\hline & Determiners & 110 & 15.2 & 19 & 6.8 \\
\hline & Prepositions & 72 & 9.9 & 16 & 5.7 \\
\hline & Pronouns & 76 & 10.5 & 19 & 6.8 \\
\hline & Syntactic verbs & 48 & 6.6 & 13 & 4.6 \\
\hline & Total & 335 & 46.1 & 75 & 26.7 \\
\hline \multirow{8}{*}{ Para-syntactic } & Abbreviations & 11 & 1.5 & 7 & 2.5 \\
\hline & Interjections & 1 & 0.1 & 1 & 0.4 \\
\hline & Names & 24 & 3.3 & 4 & 1.4 \\
\hline & Numerals & 2 & 0.3 & 2 & 0.7 \\
\hline & Para-adverbs & 28 & 3.9 & 16 & 5.7 \\
\hline & Particles & 13 & 1.8 & 1 & 0.4 \\
\hline & Total & 79 & 10.9 & 31 & 11 \\
\hline & Total (All genera) & 726 & 100 & 281 & 100 \\
\hline
\end{tabular}

Based on the percentage of schema types, 100 schemata were chosen to develop the items of achievement S-Test. It consisted of $5(5 \%)$ adjectives, 2 (2\%) adverbs, 22 (22\%) nouns, 20 (20\%) verbs, 3 (3\%) conjunctions, 16 (16\%) determiners, $11(11 \%)$ prepositions, $11(11 \%)$ pronouns, $2(2 \%)$ syntactic verbs, $3(3 \%)$ abbreviations, and $5(5 \%)$ paraadverbs. (The test is not given to save space. Interested readers can, however, contact the first author for a copy.) Similar to the 83-item pre-S-Test, the keyed responses were presented along with three competitives which had semantic, syntactic and discoursal relationships with each other and other schemata comprising the four lessons.

\section{Matching Vocabulary Test}

The 282 semantic schema types comprising the English book 2 (Birjandi \& Soheili, 2009a) and English book 3 (Birjandi \& Soheili, 2009b) as well 175 used in the first four lessons of English Book 3 (Birjandi, et al., 2012) were closely scrutinized to develop 60 short definitions. Following Schmitt, Schmitt and Clapham (2001), the definitions were presented in twenty clusters having six alternatives as shown in the example below. Similar to Khodadady, Pishghadam and Fakhar (2010), the participants were asked to match the definitions with the alternatives to reveal their vocabulary knowledge. (The test is not given to save space. Interested readers can, however, contact the first author for a copy.)

THREE EXAMPLE ITEMS OF MATCHING VOCABULARY TEST

\begin{tabular}{|llllll|}
\hline 1 & the colour of night & A & old & B & careless \\
2 & not new & C busy & D cheap \\
3 & you should wash it & E black & F & dirty \\
\hline
\end{tabular}

\section{Grammar Multiple Choice Item Test}

A grammar Multiple Choice Item Test (MCIT) was designed in order to study the SBT and TBT groups' learning of syntactic knowledge. It consisted of 30 MCIs addressing the grammatical points taught in grades 2 and 3 guidance schools and grade 1 high school. (The test is not given to save space. Interested readers can, however, contact the first author for a copy.) To design the test, the researchers benefited from some weblogs and books containing traditional school exams. Meanwhile, the analyzed schemata were frequently checked to present the points with the schemata the learners were familiar with. The MCI below, for example, measures the participants' knowledge of imperatives:

Context:

Alternatives:
EXAMPLE GRAMMAR MCI

Please ... to the blackboard.

$\begin{array}{lll}\text { A. come } & \text { C. to come } & \text { B. comes }\end{array}$
D. coming

\section{Unseen Reading MCIT}

In order to measure the participants' ability to apply what they had learned to read and understand unseen passages, the researchers chose eight paragraphs from weblogs in general and Introductory Steps to Understanding (Hill, 2004) in particular to develop a reading comprehension MCIT. (The test is not given to save space. Interested readers can, however, contact the first author for a copy.) In order to ensure that the learners knew the constituting schemata of the 
unseen passages, they were checked against the schema types comprising the texts taught. Adopting this process resulted in choosing some paragraphs which lacked MCIs. For these paragraphs, the present researchers themselves developed MCIs. MCI below provides an example of 23 items comprising the unseen reading MCIT.

\begin{tabular}{|c|c|c|}
\hline \multicolumn{3}{|c|}{ EXAMPLE UNSEEN READING MCI } \\
\hline Context: & $\begin{array}{l}\text { Mr Karami was a farmer. He a } \\
\text { hard. ... }\end{array}$ & hings and they had a few cows. They worked very \\
\hline Stem & Mr. and Mrs. Karami ... & \\
\hline Alternatives: & $\begin{array}{l}\text { A. walked in town for } 2 \text { hours. } \\
\text { B. were farmers. }\end{array}$ & $\begin{array}{l}\text { C. always ate a little. } \\
\text { D. didn't like cooking. }\end{array}$ \\
\hline
\end{tabular}

\section{Procedures}

After talking and explaining the purpose of the present study, one of the colleagues of the second author agreed to teach her two G1HS classes as she always did and administer all the tests designed in the project to her students. Upon her agreement, the pre S-Test was administered to the four classes taught by the second author and her colleague in four different schools. The t-test analysis of test results, however, showed that the mean score of two classes differed significantly from the other two. The two classes whose mean scores did not differ significantly from each other were, therefore, chosen and assigned to two groups, i.e., SBT and TBT. The former was taught by the second researcher in Taghva and the latter by her colleague in Fatemeh-ol-Zahra high schools. Both groups were taught two times a week on odd and even days. The session on odd days lasted for 90 minutes and the other 45 . In order to have a complete 90 minute session, the even sessions were mixed and were held every other week. The achievement S-Test, grammar MCIT, matching vocabulary test and unseen reading comprehension MCIT were administered to the participants as soon as the first four lessons of English book 3 (Birjandi \& Soheili, 2009b) were taught to both groups as outlined below.

\section{Translation-Based Teaching}

The key words of the passages were read by the teacher aloud and the students repeated; then, the Persian equivalents of these words were presented by the teacher. The students had to pronounce the English words correctly and memorize their Persian eqiuvalents in order to be able to translate the reading passages. Then, the "new words" appearing at the beginning of each lesson were translated by the students under the teacher's supervision. For teaching reading, the teacher had the students read the passage at home once or twice to get the general idea. Before reading them in the class, the teacher, however, raised some general questions in English. For example, she asked, "What was the passage about?" or "Which part did you like the most?" Then, she read the whole passage twice. Afterwards, it was the time for students to translate the paragraphs in groups. They could ask questions whenever needed. Answering the reading exercises was the next stage. Grammar points were taught by giving some some sentences to the students and asking them to compare them with each other in order to deduce the point. Grammar exercises were answered immediately after teaching the students in groups.

\section{Schema-Based Teaching}

At the beginning of the school year, the teacher familiarized the students with schema domains and provided them with some examples. Then, she divided the class into five groups, four of which consisted of four members and the last consisted of five. The group members had to sit beside each other each session. If any problems occurred in the structure of groups for important reasons, their members were changed for the coming sessions. Although the teacher intended to teach the classes in English, the language proficiency level of the students forced her to use Persian occasionally and whenever necessary.

For learning the underlined "New Words", the students in each group were instructed to read the sentences in which they occurred, guess their meaning and then write them on a piece of paper and give them to the teacher. While the teacher checked what they had written on paper, she had all the new schemata written on the board. Then the teacher pronounced them one by one and had the students repeat them after her. Upon ensuring that they pronounced all the new schemata correctly, she checked the equivalents given. She made use of the definitions, pictures or other means to help the students get the right meaning whenever she realized they had guessed mistakenly. For example, in lesson three all the groups had got the right meanings for pan, fire, boil, servant, few, forget and outside but some had problems guessing the meanings of find, wise and left.

To help the students understand the meaning of find in "Maryam can't find her notebook. She doesn't know where it is", the teacher asked the students what type of schema it was. Some said, "verb". When she asked "Why?" they replied, "Because it is preceded by can't". At this time, the teacher began to search her own bag. "Where is my blue pen?" she said, "I can't find it." And repeated it several times. One of the students said suddenly, "peida kærdæn/", the exact persian equivlanet of "find". The same procedure was folowed for the schemata whose meaning were not appropriately guessed.

For teaching reading comprehension, the teacher read each passage of the four lessons once and had the students listen carefully. Then, she read it for the second time and asked them to underline the unfamiliar schemata in the text. Again, the students were encouraged and led to discuss the new unknown schemata and guess their meaning on the basis of their context. Whenever they had a problem guessing the meaning, the teacher benefited from the genus the 
schema belonged to and related it to their background knowledge. For example, part of the passage taught in lesson two reads: "These monkeys live in the jungles of hot lands. There, farmers raise coconuts in fields." Some students had underlined raise and offered "pick"as its synonym. The teacher asked, "What genus does pick belong to?" One of them said, "it is a verb and it shows an action". The teacher then asked, "What else do the faremers do in their fields?" After a pause, she wrote, "raise = grow" on the board. The students got the meaning immediately since they had learned the schema "grow" in lesson one.

Upon insuring that the learners had formed the relevant mental image of all the schemata taught in their minds, the teacher helped them relate them to each other through oral summarization to develop their speaking ability. For example, she wrote the title of the second passage, "The funny farmhand", in the center of the board and asked the students to talk about it. One of the students volunteered the sentene, "monkeys are farmhands". The teacher drew a line to the top left and wrote "is a monkey" so that the students can realize that the three schemata "the", "funnay and "farmhand" form a phrase which can be replaced by "it" and the succeding verb must therefore be singular, i.e., is. One of the high-ability students realized the teacher's intention and said "is clever". To appreciate her contribution, the teacher wrote it on the top center of the board and related it to the topic with a line as shown in Figure 1.

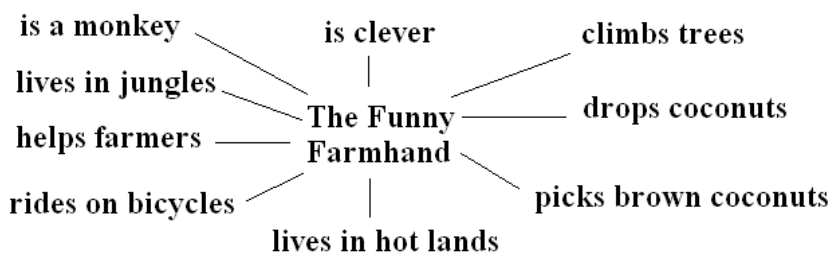

Figure 1. Developing the schema "farmhand" and relating it semantically to other schemata

Upon ensuring that the learners could produce the schemata comprising the passage themselves, the teacher taught the new grammatical point indeductively. For example, she wrote, "Friedrich can play. He could play yesterday." Then she looked at the students and said, "Could is the past form of can." A student said loudly. "Oh, yes. That's right." Encouraging her to contribute to the lesson further, the teacher immediately asked,"so what genus is it?" " Well, it is a syntactic verb," she answered. "Why?" asked the teacher again. Another student replied, "because it comes before the main verb."

- "How should we use the main verb after could?"

- "Infinitive without to."

- "Well done! Can you tell me what the negative form of could is?"

- "Couldn't. "

\section{Data Analysis}

The reliability of five tests developed in this study was estimated by employing Cronbach's Alpha. The internal validity of the tests was determined by utilizing the item facility (IF) and item discrimination (ID) indices. While the IF index was calculated as the proportion of correct responses given to a specific item, it was correlated by the total score to obtain the biserial correlation coefficients as its ID index. Items having the IF indices falling between 0.25 to 0.75 (Baker, 1989) and ID indices equal to and higher than 0.25 were considered well functioning. And finally the One-Way ANOVA analysis was utlized to explore the difference in the mean scores of the SBT and TBT groups on the tests. All the statistical analyses were carried out via the IBM SPSS statistics 20.0 to test the hypothesis that there will be no significant difference in the mean scores of SBT and TBT groups on the tests administered after the course content is taught.

\section{RESULTS}

Table 3 presents the descriptive statistics and reliability estimates of the five tests designed and administered in this study. As can be seen, the alpha reliability coefficient (RC) of the achievement S-Test is the highest (.96), followed by the matching vocabulary test (.93) and pre-S-Test (.90). Although the grammar MCIT has the lowest RC (.56) it has functioned well psychometrically and differentiated high from low achievers in that its 15 (50\%) items have acceptable IF and ID indices, i.e., items 1, 2, 4, 5, 6, 14, 15, 16, 17, 18, 19, 22, 24, 25 and 27. As the mean IF (.40) shows the grammar MCIT occupies the second position in terms of difficulty level among the tests administered after the treatment. 
TABLE 3

DESCRIPTIVE STATISTICS AND RELIABILITY ESTIMATES OF TESTS

\begin{tabular}{|c|c|c|c|c|c|c|c|c|}
\hline Tests & Groups & $\mathbf{N}$ & Mean & SD & Std. Error & Mean IF & Mean ID & Alpha \\
\hline \multirow{3}{*}{ Pre-S-Test } & TBT & 20 & 33.90 & 13.114 & 2.932 & \multirow{3}{*}{.38} & \multirow{3}{*}{.32} & \multirow{3}{*}{.90} \\
\hline & SBT & 21 & 29.67 & 12.595 & 2.748 & & & \\
\hline & Total & 41 & 31.73 & 12.869 & 2.010 & & & \\
\hline \multirow{3}{*}{ Achievement S-Test } & TBT & 20 & 49.50 & 23.105 & 5.166 & \multirow{3}{*}{.50} & \multirow{3}{*}{.45} & \multirow{3}{*}{.96} \\
\hline & SBT & 21 & 50.71 & 21.673 & 4.729 & & & \\
\hline & Total & 41 & 50.12 & 22.109 & 3.453 & & & \\
\hline \multirow{3}{*}{ Grammar } & TBT & 20 & 12.60 & 4.173 & .933 & \multirow{3}{*}{.40} & \multirow{3}{*}{.27} & \multirow{3}{*}{.56} \\
\hline & SBT & 21 & 11.81 & 3.558 & .776 & & & \\
\hline & Total & 41 & 12.20 & 3.842 & .600 & & & \\
\hline \multirow{3}{*}{ Vocabulary } & TBT & 20 & 27.80 & 11.998 & 2.683 & \multirow{3}{*}{.41} & \multirow{3}{*}{.45} & \multirow{3}{*}{.93} \\
\hline & SBT & 21 & 22.67 & 14.015 & 3.058 & & & \\
\hline & Total & 41 & 25.17 & 13.166 & 2.056 & & & \\
\hline \multirow{3}{*}{ Unseen Reading } & TBT & 20 & 7.40 & 3.575 & .799 & \multirow{3}{*}{.38} & \multirow{3}{*}{.42} & \multirow{3}{*}{.79} \\
\hline & SBT & 21 & 10.29 & 5.149 & 1.124 & & & \\
\hline & Total & 41 & 8.88 & 4.632 & .723 & & & \\
\hline
\end{tabular}

As it can also be seen in Table 3 above, in terms of reliability, the unseen reading MCIT has the second lowest RC (.79). The relatively low RC of the test is due to its difficulty level as reflected in the mean IF (.38). The RC of the test is, however, much higher than that of the grammar MCIT (.56) because out of 23 items, 19 (82.6\%) have functioned well, i.e., 2, 3, 4, 5, 8, 9, 10, 11, 12, 13, 14, 15, 16, 17, 18, 19, 21, 22, and 23. Similarly, as the measure enjoying the highest RC (.96), the achievement S-Test has the most well functioning items (84 out of 100), i.e., items 2 , $4,7,8,9,11,12,14,16,18,19,21,22,23,25,26,28,29,30,31,32,33,34,35,36,37,38,39,41,42,43,44,45,46$, $47,48,49,50,51,52,53,54,55,57,58,59,60,61,62,63,64,65,66,67,68,69,70,71,72,73,74,76,77,78,79,80$, $81,82,83,84,86,87,88,89,90,91,92,93,95,96,97,98,99$, and 100 . Similarly, out of the 60 items comprising the matching vocabulary test, 47 (78.3\%) have functioned well, i.e., 1, 2, 3, 4, 5, 6, 7, 8, 9, 10, 11, 12, 13, 15, 16, 19, 21, 22, 23, 24, 26, 27, 28, 29, 30, 31, 32, 36, 37, 38, 39, 40, 41, 42, 43, 44, 45, 47, 49, 50, 51, 52, 54, 55, 57, 59, 60.

Table 4 presents the One-Way ANOVA analysis of mean scores obtained on the five tests. As can be seen, the SBT group has performed significantly better than their TBT counterpart only on the unseen reading comprehension MCIT $(\mathrm{F}=4.303, \mathrm{df}=1, p<.05)$. The effect size, calculated using eta squared, was .10 , revealing a medium effect according to Cohen's (1988) classification. These results reject the null hypothesis that there will be no significant difference in the mean scores of SBT and TBT groups on the tests administered after the course content is taught. They support the studies reporting the superiority of SBT over TBT (Khodadady et al., 2012; Khodadady \& Elahi, M. (2012)

TABLE 4

ONE-WAY ANOVA ANALYSIS OF MEAN SCORES OBTAINED ON THE TESTS

\begin{tabular}{|c|c|c|c|c|c|c|}
\hline & & Sum of Squares & df & Mean Square & $\mathrm{F}$ & Sig. \\
\hline \multirow{3}{*}{ Pre-S-Test } & Between Groups & 183.582 & 1 & 183.582 & 1.112 & .298 \\
\hline & Within Groups & 6440.467 & 39 & 165.140 & & \\
\hline & Total & 6624.049 & 40 & & & \\
\hline \multirow{3}{*}{ Achieve S-Test } & Between Groups & 15.105 & 1 & 15.105 & .030 & .863 \\
\hline & Within Groups & 19537.286 & 39 & 500.956 & & \\
\hline & Total & 19552.390 & 40 & & & \\
\hline \multirow{3}{*}{ Grammar } & Between Groups & 6.401 & 1 & 6.401 & .427 & .517 \\
\hline & Within Groups & 584.038 & 39 & 14.975 & & \\
\hline & Total & 590.439 & 40 & & & \\
\hline \multirow{3}{*}{ Vocabulary } & Between Groups & 269.938 & 1 & 269.938 & 1.580 & .216 \\
\hline & Within Groups & 6663.867 & 39 & 170.868 & & \\
\hline & Total & 6933.805 & 40 & & & \\
\hline \multirow{3}{*}{ Unseen Reading } & Between Groups & 85.305 & 1 & 85.305 & 4.303 & .045 \\
\hline & Within Groups & 773.086 & 39 & 19.823 & & \\
\hline & Total & 858.390 & 40 & & & \\
\hline
\end{tabular}

\section{DISCUSSIONS AND CONCLUSION}

In countries where English is taught as a foreign language, teaching reading may be more important than the oral use of language (Day, 2003). TBT has been employed to accomplish the task for centuries (Richards \& Rodgers, 2001). However, many scholars such as Day (2003) believed that reading and translation are two different abilities. While reading is basically a monolingual interactive process in which readers interact with the text to construct meaning (Adams \& Collins, 1977; Day, 2003; Khodadady \& Elahi, 2012), translation requires going through the same process in two languages. The SBT and TBT, therefore, differ from each other because the former requires activating and applying the schemata in English whereas the latter dependes on the first langauge which happens to be Persian in this study. 
The present study, however, differs from the mainstream approach towards the concept of background knowledge by approaching schemata from a microstructural perspective. While marostructural approach adopts a given text as a schema and explains reading as an interpretation process "guided by the principle that every input is mapped against existing schema and that all aspects of that schema must be compatible with the input information" (Carrell, 1983), the microstructural approach adopts each single or phrasal word used in a text as a schema and emphasises not only its comprehension by readers as a result of creating its map in their minds but also its being shaped and modified by other schemata constituting the text. In other words, while macrostructural approach views a schema as a static concept which "must be compatible with the input information", the microstructual approach renders it dynamic by placing it within a text/context in which its meaning depends on the syntactic, semantic and discoursal relationships it holds with other schemata constituting the context/text.

Since there is no entry for the compound noun "farmhand", for example, in The Shorter Oxford English Dictionary (Onions, 1973), it can be safely assumed that it did not exist in the mind of any British reader untill 1973. The readers of Longman Dictionary of Contemporary English (1995), however, have already created a mental image of the noun in their minds because they know that it represents "someone who works on a farm" (p. 502). The participants of the present study would have serious difficulty in reading and understanding the passage "The Funnary Farmhand" if they follow the macrostructural approach and create the image of "someone" rather than "a monkey" in their minds as they go through the passage. The TBT group of the present study ould face the same difficulty if they translated "farmhand" as KAREHGAR MAZRAEH (Aryanpur Kashni, 1377, p. 506) which defines it as a "person" rather than "an animal" working on a farm.

The results of the present study show that helping English learners create mental concepts in English rather than in Persian and then relate them to other concepts expressed by the schemata comprising the text enables them to read unseen passages and understand them better than those who activate the same concepts in their first language statically and thus fail to improve them in the light of what they read. Reading comprehension ability is, therefore, a process of activating one's previously acquired knowlede of each schema appearing in a text and enriching it by relating it to other schemata comprising the text. The SBT group of the present study, for example, learned that a farmhand can be "a funny and clever monkey who can ride on a back of bicycle to reach a farm to pick up ripe coconuts".

The establishment and enrichment of schemata via SBT is a multidimensional process in which syntax, semantics and discourse are employed simultaneously by parsing, identifying and categorising the schemata comprising the texts into their syntactic, semantic and parasyntactic domains, genera, species and types. The schema "farmhand", for example, is a type of compound noun species forming the noun genus of semantic domain. The teachers will be eductionally well equipped if they schematically analyse the texts they want to teach and define their course objectives on the bais of this analysis. For example, the analysis of the four lessons taught in this study shows that the teachers' main job is to teach $175(62.5 \%)$ semantic, $75(26.5 \%)$ syntactic and $31(11 \%)$ parasyntactic schema types. Since most of the schemata to be taught are semantic in nature, they should not, therefore, devote the main part of their time to grammar as TBT does.

As the results of this study show SBT brings about significantly higher achievement as reflected in reading unseen passages. Higher achievement could not, however, be shown on achievement S-Test, grammar MCIT and matching vocabulary test as a result of some intervening variables. First, the students in TBT group were studying in a boarding school; thus, they came from different villages in Koohsorkh. The SBT group were, however, studying in a daily school. The former group is more motivated than the latter as reflected in their non-signicantly higher mean score on the pre STest (33.90 vs 29.27). It is, therefore, suggested that the study be replicated with more homogenous groups. For example, both SBT and TBT groups be chosen from boarding schools.

In addition to having participants from two different types of high schools, the teachers offering the course were different. The second author taught the SBT group while the TBT group was taught by a colleague of hers. Since the authors could not observe al the sessions offered in the TBT, the teacher might have done some extra activities to provide a more favourable picture of her teaching. It is, therefore, suggested that the study be replicated by having both groups be taught by the same teacher as Khodadady and Elahi (2012) did. Alternatively, groups with almost the same mean scores on pretest should be chosen by encouraging more teachers to take part in the project.

\section{APPENDIX. PRE S-TEST}

Direction: Read the passages below and choose the best answer marked A, B, C and D. After choosing the best answer, fill in the box corresponding to the number of question in your answer sheet.

\section{Passage 1:}

This is a picture of a ...1... You see some people in ....2.... Mohsen and his father are sitting .......... a bench. Mohsen's father is ...4... a newspaper. But Mohsen is eating some ...5..... He is fifteen years old. There is a small ...6... on the bench. It's Mohsen's bag. You see a small ...7 ... near them. The wheels of the bicycle are small, too. It isn't Mohsen's bicycle. .....8.... bicycle is big. 


\begin{tabular}{|c|c|c|c|c|c|c|c|c|}
\hline 1 & $\mathbf{A}$ & hospital & B & park & $\mathbf{C}$ & school & D & library \\
\hline 2 & $\mathbf{A}$ & it & B & him & $\mathbf{C}$ & them & D & her \\
\hline 3 & $\mathbf{A}$ & in & B & on & $\mathrm{C}$ & by & D & under \\
\hline 4 & A & eating & B & leaving & C & reading & D & teaching \\
\hline 5 & $\mathbf{A}$ & milk & B & tea & $\mathrm{C}$ & ice-cream & D & water \\
\hline 6 & $\mathbf{A}$ & bench & B & bicycle & $\mathrm{C}$ & bag & D & picture \\
\hline 7 & $\mathbf{A}$ & bench & B & bicycle & C & bag & D & picture \\
\hline 8 & $\mathbf{A}$ & Her & B & His & $\mathbf{C}$ & Your & D & My \\
\hline
\end{tabular}

\section{Passage 2:}

My father has a lot of books. He reads different books. He usually ...9... after dinner. He ....10... books are our good friends. They teach us a lot of things. He buys several books . ...11... month. He buys some books for ....12... and my sister, too. My sister ....13... about 4. She likes books with ....14... in them. She learns many things from them. I like my books ...15... much. They are my good friends ...16... teachers. I usually read them after I do my homework.

\begin{tabular}{|c|c|c|c|c|c|c|c|c|}
\hline 9 & $\mathbf{A}$ & walks & B & eats & C & wakes up & D & reads \\
\hline 10 & A & speaks & B & listens & C & says & D & looks \\
\hline 11 & $\mathbf{A}$ & all & B & every & $\mathrm{C}$ & some & D & many \\
\hline 12 & $\mathbf{A}$ & us & $\mathbf{B}$ & him & $\mathbf{C}$ & them & D & me \\
\hline 13 & $\mathbf{A}$ & $\mathrm{am}$ & B & is & $\mathrm{C}$ & have & D & has \\
\hline 14 & $\mathbf{A}$ & pictures & B & problems & $\mathrm{C}$ & programs & D & places \\
\hline 15 & $\mathbf{A}$ & very & B & not & $\mathrm{C}$ & every & D & how \\
\hline 16 & $\mathbf{A}$ & but & B & and & $\mathbf{C}$ & that & D & when \\
\hline
\end{tabular}

\section{Passage 3:}

$\ldots 17 \ldots$ are many animals in the zoo. Many of ...18... are wild. Lions and ...19... are wild animals. Some of these wild animals come ...20... Africa. Some of the ...21... in the zoo are not wild. Camels and ...22... are not wild. Wild animals eat a lot of food. Tigers and lions eat a lot of ...23....

\begin{tabular}{|c|c|c|c|c|c|c|c|c|}
\hline 17 & $\mathbf{A}$ & They & B & You & C & There & D & $\mathrm{We}$ \\
\hline 18 & $\mathbf{A}$ & them & B & us & $\mathbf{C}$ & him & D & me \\
\hline 19 & $\mathbf{A}$ & horses & B & camels & $\mathbf{C}$ & tigers & D & cats \\
\hline 20 & $\mathbf{A}$ & in & B & on & $\mathbf{C}$ & by & D & from \\
\hline 21 & $\mathbf{A}$ & lions & B & animals & $\mathbf{C}$ & tigers & D & camels \\
\hline 22 & $\mathbf{A}$ & horses & B & lions & C & tigers & D & dogs \\
\hline 23 & $\mathbf{A}$ & milk & B & meat & $\mathbf{C}$ & fruits & D & bread \\
\hline
\end{tabular}

\section{Passage 4:}

Every morning Mahmood and his friend, Mehdi, walk to ...24... . They are ...25... at school before eight o'clock.

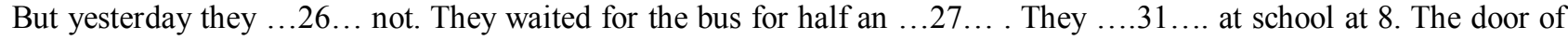
the classroom was not ...28... Mehdi opened the door and they ...29... in. Their ...30... was not in the classroom. Mehdi and his friend walked to ....31... desks. A few minutes ...32...., the teacher opened the door and walked in. He said hello to his students. They opened their books and ....33 .... to the teacher.

\begin{tabular}{|c|c|c|c|c|c|c|c|c|}
\hline 24 & $\mathbf{A}$ & work & B & school & $\mathbf{C}$ & class & D & home \\
\hline 25 & $\mathbf{A}$ & never & B & sometimes & C & usually & D & always \\
\hline 26 & $\mathbf{A}$ & was & B & will & C & were & D & are \\
\hline 27 & $\mathbf{A}$ & evening & B & afternoon & $\mathbf{C}$ & accident & & hour \\
\hline 28 & A & waited & B & walked & C & arrived & D & left \\
\hline 29 & $\mathbf{A}$ & open & B & ready & $\mathrm{C}$ & closed & D & heavy \\
\hline 30 & $\mathbf{A}$ & waited & B & walked & $\mathrm{C}$ & arrived & D & left \\
\hline 31 & $\mathbf{A}$ & friends & B & parents & $\mathrm{C}$ & teacher & D & brother \\
\hline 32 & $\mathbf{A}$ & his & B & her & C & our & D & their \\
\hline 33 & $\mathbf{A}$ & ago & B & yet & $\mathrm{C}$ & now & D & later \\
\hline 34 & $\mathbf{A}$ & pointed & B & listened & $\mathbf{C}$ & spoke & D & walked \\
\hline
\end{tabular}

\section{Passage 5:}

My family and I ...35 ... to Mashhad two years ago. We stayed ...36... for two weeks. We had a very good time there. We visited many places. We went to the Holy Shrine several ...37... . A lot of people ...38... to Mashhad each year. They come from ....39.... parts of the country. Last summer my friend, Nahid, went to Shiraz. Her ....40.... come from Shiraz. ...41... they live in Tehran. She stayed in her grandfather's house. Her uncles and aunt ....42... there, ...43... . They were very kind and Nahid .....44.... her visit very much. 


\begin{tabular}{|c|c|c|c|c|c|c|c|c|}
\hline 35 & $\mathbf{A}$ & go & B & goes & $\mathbf{C}$ & will go & D & went \\
\hline 36 & $\mathbf{A}$ & this & B & there & $\mathrm{C}$ & that & D & here \\
\hline 37 & $\mathbf{A}$ & tickets & B & times & C & things & D & towns \\
\hline 38 & $\mathbf{A}$ & go & B & goes & $\mathbf{C}$ & Will go & D & went \\
\hline 39 & $\mathbf{A}$ & different & B & cheap & $\mathbf{C}$ & heavy & D & dirty \\
\hline 40 & $\mathbf{A}$ & friends & B & teachers & $\mathbf{C}$ & children & D & parents \\
\hline 41 & $\mathbf{A}$ & Soon & B & Next & C & Now & D & Later \\
\hline 42 & $\mathbf{A}$ & like & B & leave & $\mathbf{C}$ & live & D & look \\
\hline 43 & $\mathbf{A}$ & so & B & too & $\mathbf{C}$ & very & D & perhaps \\
\hline 44 & $\mathbf{A}$ & helped & B & enjoyed & $\mathbf{C}$ & spent & D & bought \\
\hline
\end{tabular}

\section{Passage 6:}

Mr Irani goes shopping every Thursday. He usually ....45... some fruits, vegetables and other things. Last Thursday, he went shopping with ...46... friend, Mr Taheri. They ....47... a taxi to the shopping center. There were a lot of ....48 ... in the shopping center. They ...49... many things: apples, peaches, onions, and potatoes. On the way home

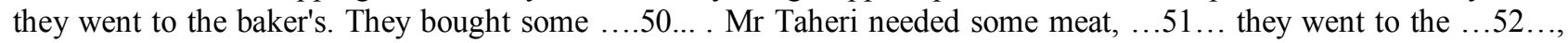
too.

\begin{tabular}{|l|l|l|l|l|l|l|l|l|}
\hline 45 & A & gives & B & begins & C & buys & D & knows \\
\hline 46 & A & her & B & their & C & its & D & his \\
\hline 47 & A & took & B & talked & C & thought & D & taught \\
\hline 48 & A & teachers & B & farmers & C & shoppers & D & drivers \\
\hline 49 & A & began & B & bought & C & broke & D & brought \\
\hline 50 & A & fruits & B & vegetables & C & milk & D & bread \\
\hline 51 & A & so & B & but & C & then & D & because \\
\hline 52 & A & baker's & B & library & C & butcher's & D & shopping center \\
\hline
\end{tabular}

\section{Passage 7:}

It is Thursday. There is a football ....53 .... at Azadi Stadium. We are going to the stadium this afternoon. Everybody can see the match. They can stay at home and ...54 .. TV. We should ....55... home at one. We may take a taxi. We should be ....56.... They close the doors of the stadium at $2: 45$. We don't want to be ...57... . But many people go by ...58 ... because it's very cheap. People ....59.... have a good time at the stadium. My friends and I ...60... go there by bus. We don't take a taxi because it's ....61.... . Young people usually go the stadium for football matches. They have a good time there and enjoy the ...62....

\begin{tabular}{|l|l|l|l|l|l|l|l|l|}
\hline 53 & A & game & B & program & C & news & D & match \\
\hline 54 & A & see & B & look & C & visit & & watch \\
\hline 55 & A & go & B & take & C & leave & D & get \\
\hline 56 & A & in time & B & late & C & soon & D & ready \\
\hline 57 & A & in time & B & late & C & soon & D & ready \\
\hline 58 & A & taxi & B & bicycle & C & bus & D & car \\
\hline 59 & A & can & B & do & C & should & D & does \\
\hline 60 & A & never & B & sometimes & C & ever & D & usually \\
\hline 61 & A & old & B & expensive & C & cheap & D & new \\
\hline 62 & A & cartoons & B & films & C & news & D & games \\
\hline
\end{tabular}

\section{Passage 8:}

Mr Kamali and his family are from Tehran. They now live ...63... Birjand. They had a difficult ...64... in Tehran. They think people in small towns have a ...65... life. They don't ...66... many of problems that people have in big cities. There are not many ...67... in the streets. And they don't ...68... a lot of time in the heavy traffic every day. They can get the things they need easily and ...69... People are not always in a ...70... They have a lot of ...71 .. time. They can visit their relatives and friends. People are not very ....72 ... in small towns. And they help you ...73 ... you need them.

\begin{tabular}{|l|l|l|l|l|l|l|l|l|}
\hline 63 & A & on & B & at & C & in & D & to \\
\hline 64 & A & lunch & B & life & C & lesson & D & lion \\
\hline 65 & A & hard & B & happy & C & heavy & D & holy \\
\hline 66 & A & have & B & get & C & help & D & need \\
\hline 67 & A & games & B & benches & C & tickets & D & cars \\
\hline 68 & A & spend & B & want & C & sleep & D & walk \\
\hline 69 & A & hard & B & carefully & C & fast & D & carelessly \\
\hline 70 & A & hour & B & hair & C & house & D & hurry \\
\hline 71 & A & hard & B & free & C & busy & D & bad \\
\hline 72 & A & free & B & dirty & C & busy & D & ready \\
\hline 73 & A & when & B & and & C & that & D & but \\
\hline
\end{tabular}

\section{Passage 9:}


Tomorrow Hamid will ...74.... at half past five. He will wash and pray. Then he will ...75... his breakfast. They usually have bread and cheese for ...76... He will put on his ...77... He will go to school by bus. His first lesson, English, will begin at eight o'clock. He will have ...78 .. break at 9:30. After the break, ...79... will have Arabic. After ...80..., all the students will go home. He will get home at 12:30. He will have his lunch at 1:30. After lunch, he will ...81 ... his homework, and ...82 .. he will watch ..83 ... He usually goes to bed at 9:30.

\begin{tabular}{|c|c|c|c|c|c|c|c|c|}
\hline 74 & $\mathbf{A}$ & get up & B & sleep & $\mathbf{C}$ & go to bed & D & sit \\
\hline 75 & $\mathbf{A}$ & drink & B & read & $\mathrm{C}$ & say & D & have \\
\hline 76 & $\mathbf{A}$ & breakfast & B & lunch & $\mathrm{C}$ & evening & D & dinner \\
\hline 77 & $\mathbf{A}$ & bag & B & clothes & $\mathrm{C}$ & watch & D & dress \\
\hline 78 & $\mathbf{A}$ & some & B & two & $\mathrm{C}$ & $\mathrm{a}$ & D & the \\
\hline 79 & $\mathbf{A}$ & we & B & you & $\mathrm{C}$ & they & D & she \\
\hline 80 & $\mathbf{A}$ & sleep & B & home & $\mathrm{C}$ & school & D & Break \\
\hline 81 & $\mathbf{A}$ & have & B & do & $\mathrm{C}$ & take & D & Get \\
\hline 82 & $\mathbf{A}$ & so & B & now & $\mathrm{C}$ & perhaps & D & then \\
\hline 83 & $\mathbf{A}$ & picture & B & relative & $\mathrm{C}$ & television & D & phone \\
\hline
\end{tabular}

This is the end of the test.

\section{REFERENCES}

[1] Adams, M. J., \& Collins, A. (1977). A schema theoretic view of reading. Cambridge: Bolt Beranek and Newman Inc.

[2] Aryanpur Kashni, M. (1377). The Aryanpur progressive English-Persian dictionary one volume. Tehran: Jahan Rayaneh.

[3] Baker, D. (1989). Language testing: a critical survey and practical guide. London: Edward Arnold

[4] Ajideh, P. (2003). Schema theory-based pre-reading tasks: a neglected essential in the ESL reading class. The Reading Matrix, $3(1), 1-14$.

[5] Birjandi, P., Soheili, A., Nouroozi, M., \& Mahmoodi, G. (2012). English book 3. Tehran: Ketabhaye Darsie Iran Publication.

[6] Birjandi, P., \& Soheili, A. (2009a). English book 2. Tehran: Ketabhaye Darsie Iran Publication.

[7] Birjandi, P., \& Soheili, A. (2009b). English book 3. Tehran: Ketabhaye Darsie Iran Publication.

[8] Brown, H. D. (2000). Principles of language learning and teaching (4th ed.). San Francisco: Addison Wesley.

[9] Carrell, P. L. (1983). Some issues in studying the role of schemata, or background knowledge, in second language comprehension. TESOLConvevtion (pp. 81-92). Toronto: Canada.

[10] Carrell, P. L. (1984). Schema theory and ESL reading: classroom implications and applications. The Modern Language Journal, 68(4), 332-343

[11] Carrell, P., \& Floyd, P. (1989). Effects on ESL reading of teaching cultural content schemata. Language Learning, 37, 88-108.

[12] Cohen, J, W. (1988). Statistical power analysis for the behavioral sciences ( $2^{\text {nd }}$ ed.). Hillsdale, NJ: Lawrence Erlbaum Associations.

[13] Day, R. R. (2003). Teaching reading and grammar translation. Retrieved from CAPE Alumni Internet Connection: English Teacher Talk.

[14] Hill, L. A. (2004). Introductory steps to understanding. Khatereh: Mashhad.

[15] Khodadady, E. (1999). Multiple choice items in testing: practice and theory. Tehran: Rahnama.

[16] Khodadady, E. (2008). Schema-based textual analysis of domain-controlled authentic texts. Iranian Journal of Language Studies , 431-446.

[17] Khodadady, E., \& Elahi, M. (2012). The effect of schema-vs-translation-based instruction on Persian medical students' learning of general English. English Language Teaching, 5 (1), 146-165. URL: http://dx.doi.org/10.5539/elt.v5n1p146.

[18] Khodadady, E., \& Herriman, M. (2000). Schemata Theory and Selected Response Item Tests: From Theory to Practice. In A. J. Kunan (Ed.), Fairness and validation on language assessment (pp. 201-222). Cambridge: CUP.

[19] Khodadady, E., \& Javadi Mehr, S. (2012). Schema-based analysis of gendered self-disclosure in persian: writing for dating context. English Language Teaching , 5, 20-31.

[20] Khodadady, E., Alavi, M., Pishghadam, R., \& Khaghaninezhad, M., S. (2012). Teaching General English in Academic Context: Schema-Based or Translation-Based Approach?. International Journal of Linguistics, 4 (1). 56-89. URL: http://dx.doi.org/10.5296/ijl.v4i1.1213.

[21] Khodadady, E., Pishghadam, R., \& Fakhar, M. (2010). The relationship among reading comprehension ability, grammar and vocabulary knowledge:An experimental and schema-based approach. The Iranian EFL Journal , 6 (2), 7-49.

[22] Larsen-Freeman, D. (2000). Techniques and principles in language teaching. Oxford: Oxford University Press.

[23] Longman. (1995). Longman Dictionary of Contemporary English Vol. 1 (3 ${ }^{\text {rd }}$ ed.). Essex, England: Longman.

[24] Melendez, E. J., \& Pritchard, R. H. (1985, October). Applying schema theory to foreign language reading. Foreign Language Annals, 18(5), 399-403.

[25] Onions, C. T. (Ed.) (1973). The shorter Oxford English dictionary ( $3^{\text {rd }}$ ed.). Oxford: Clarendon Press.

[26] Pearson, P. D., Hansen, J., \& Gordon, C. (1979). The effect of background knowledge on young choldren's comprehension of explicit and implicit information. Journal of Reading Behavior, XI(3), 201-209.

[27] Richards, J. C., \& Rodgers, T. S. (2001). Approaches and methods in language teaching (2nd ed.). Cambridge: CUP.

[28] Schmitt, N., Schmitt, D., \& Clapham, C. (2001). Developing and exploring the behavior of two new versions of the Vocabulary Levels Test. Language Testing, 18 (1), 55-88.

[29] Shejbalová, D. (2006). Methods and approaches in vocabulary teaching and their influence on students' acquisition. Department of English Language and Literature. Masaryk: Masaryk University. 
[30] Stott, N. (2001). Helping ESL students become better readers: schema theory applications and limitations. The Internet TESL Journal, VII(11).1-7.

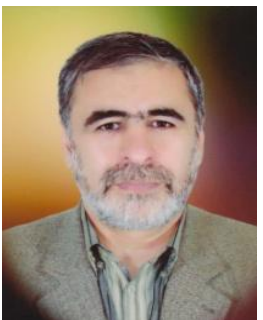

Ebrahim Khodadady was born in Iran in 1958. He obtained his $\mathrm{PhD}$ in Applied Linguistics from the University of Western Australia in 1998. He holds TESL Ontario and Canadian Language Benchmarks Placement Test (CLPBPT) certificates and has taught English as a first, second and foreign language to high school and university students in Australia, Canada and Iran.

$\mathrm{He}$ is currently an academic member of English Language and Literature Department at Ferdowsi University of Mashhad, Iran. He was invited as a VIP by Brock University in Canada in 2004 and served as the Associate Director of Assessment Center at George Brown College in Toronto for almost a year. His published books are Multiple-Choice Items in Testing: Practice and Theory (Tehran, Rahnama, 1999), Reading Media Texts: Iran-America Relations (Sanandaj, Kurdistan University, 1999) and English Language Proficiency Course: First Steps (Sanandaj, Kurdistan University, 2001). His main research interests are Testing, Language Learning and Teaching.

Dr. Khodadady is currently a member of Teaching English Language and Literature Society of Iran (TELLSI), TESL Ontario and European Society for Translation Studies. He is on the editorial board of Ferdowsi Review: An Iranian Journal of TESL, Literature and Translation Studies and has reviewed some research papers for Iranian Journal of Applied Linguistics and TESL Canada Journal as a guest reviewer.

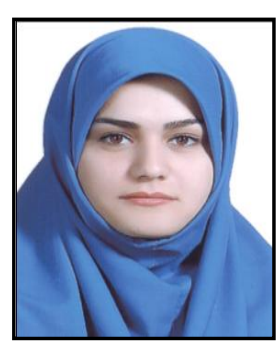

Reyhaneh Hesarzadeh was born in 1986 in Iran. She obtained her associate degree in Hasheminejad teacher training center in Mashhad (Teaching English as a Foreign Language) in 2006. Working as a teacher for ministry of education, she simultaneously obtained her B.A in Ferdowsi university of Mashhad (English language and literature) and being a top student, she was admitted as an M.A student, there. She has taught English as a foreign language in different schools in Mashhad and Kuhsorkh to junior and high school students for seven years. 